\title{
UM OLHAR SOB A PERSPECTIVA DA OFICINA "EU RECONHEÇO SINAIS DE ALERTA NO PRÉ-NATAL E PUERPÉRIO" - DISTRITO SANITÁRIO VII - RECIFE - PE
}

\author{
UNA MIRADA BAJO LA PERSPECTIVA DEL TALLER "YO RECONOZCO \\ SEÑALES DE ADVERTENCIA EN EL PRENATAL Y POSPARTO” - DISTRITO DE \\ SALUD VII - RECIFE - PE
}

\section{A LOOK FROM THE PERSPECTIVE OF THE WORKSHOP "I RECOGNIZE WARNING SIGNS IN PRENATAL AND POSTPARTUM" - SANITARY DISTRICT VII - RECIFE - PE}
Ariosto Afonso de Morais ${ }^{1}$; Thâmara Onofre de Melo $^{2}$; Fernanda Evelyn Silva ${ }^{3}$; Eliane Barbosa da Silva ${ }^{4}$; Christiane Walburga Ferreira de Azevedo ${ }^{5}$

DOI: https://doi.org/10.31692/978-65-991061-9-4.56-61

\section{INTRODUÇÃO}

De acordo com o Ministério da Saúde (BRASIL, 2019) a gravidez é um fenômeno fisiológico, de grandes transformações para a mulher, para seu (sua) parceiro (a) e para toda a família. Este período inicia-se com a fecundação, se estende por um período de cerca de 40 semanas e encerra com o parto (COUTINHO et al, 2014). A partir do nascimento e seguindo até a recuperação anatômica e fisiológica completa, está o período denominado puerpério, onde o organismo retorna às condições pré-gestacionais (SÁEZ et al., 2018); didaticamente, pode ser dividido em três fases, sendo imediato, tardio e remoto (ANDRADE et al., 2015).

A Atenção Básica é porta de entrada dos serviços de pré-natal e acompanhamento puerperal e conta com profissionais médicos e enfermeiros, que devem tratar o ciclo gravídicopuerperal de forma integrada (ANDRADE et al., 2015). Toda mulher tem direito garantido a atendimento seguro, humanizado e qualificado na gravidez, parto e após o nascimento do bebê (BRASIL, 2018).

A assistência pré-natal pode auxiliar positivamente o diagnóstico e tratamento adequado das afecções, além de fiscalizar fatores de risco que gerem complicações na saúde da mãe e do bebê, tendo também como finalidade prevenir complicações durante a gravidez e no parto; proporcionar agradável saúde materna e bom desenvolvimento fetal; e diminuir os índices de morbimortalidade fetal e materna (MARTINS et al, 2015).

\footnotetext{
${ }^{1}$ Medicina, Universidade Católica de Pernambuco, ariostodireito@yahoo.com.br

${ }^{2}$ Odontologia, Universidade Tiradentes de Pernambuco, thamaraonoffre@ hotmail.com

${ }^{3}$ Fisioterapia, Universidade Federal de Pernambuco, ferevelyn7@ gmail.com

${ }^{4}$ Enfermagem, Universidade Estadual de Pernambuco, elibarbosa2009@gmail.com

${ }^{5}$ Especialista em Saúde Pública, FIOCRUZ, christiane.walburga@ hotmail.com
} 
No puerpério a mulher apresenta inúmeras modificações internas e externas, o que configura um período repleto de mudanças psíquicas e físicas, onde ela continua necessitando de proteção e cuidado. Dessa forma, há a necessidade da usuária continuar sendo atendida em sua totalidade, por meio de um olhar integral que leve em consideração o contexto sociocultural e familiar (ANDRADE et al., 2015).

Considerada um importante indicador da realidade social de um país, a mortalidade materna é indicativo de precárias condições socioeconômicas e representa um grande problema de saúde pública por se tratar de uma morte evitável em praticamente 100\% dos casos (CARVALHO et al, 2015).

Visando a formação de profissionais cada vez mais capacitados faz-se necessário a preparação e constante atualização destes profissionais. Nesse contexto, as metodologias ativas de aprendizagem ganham espaço; uma vez que se baseiam em formas novas de desenvolver o processo de aprendizagem, estimulando processos de reflexão, mediado por facilitadores que permitam que os participantes assumam posturas ativas em relação ao seu processo de aprendizagem, a fim de solucionar situações problemas (GARCIA; OLIVEIRA; PLANTIER, 2019).

A implementação dessas metodologias favorece a motivação de cada um quando inclui o fortalecimento da percepção de ser fator modificador de seu próprio conhecimento, deste modo, as metodologias ativas têm o potencial de despertar a curiosidade, à medida que os integrantes se inserem na teorização e buscam trazer novos elementos, ainda não considerados nas aulas ou na perspectiva dos demais.

Considerando o exposto e entendendo a importância do pré-natal e acompanhamento puerperal na redução da mortalidade materna, o objetivo do presente trabalho foi descrever a aplicação da oficina "Eu reconheço sinais de alerta no pré-natal e puerpério" no Distrito Sanitário VII- Recife-PE utilizando metodologia ativa de transferência de conhecimento.

\section{FUNDAMENTAÇÃO TEÓRICA}

O Ministério da Saúde, utilizando o Programa de Humanização do Pré-natal e Nascimento (PHPN), trouxe à pauta o acesso e a qualidade do cuidado no ciclo gravídicopuerperal (CORREA et al, 2017) que respalda a busca para uma assistência mais qualificada à gestantes. Uma experiência positiva no pré-natal contribui para o alcance da qualidade, uma vez que dispõe de profissionais capacitados para identificar precocemente os fatores de risco para a mulher e controlá-los oportunamente. Dessa forma, entende-se que a qualidade da 
assistência pré-natal impacta diretamente nos indicadores de saúde (LIVRAMENTO et al, 2019).

O puerpério também é um período que requer atenção por ocorrer mudanças anatômicas, fisiológicas e transformações profundas (GOMES; SANTOS, 2017). No planejamento das ações da equipe de Atenção Básica, deve ser garantido o acompanhamento integral da mulher e da criança que devem ser assistidos por profissionais atentos e preparados para prestar assistência a mulher e sua família, para reconhecer condições de risco e vulnerabilidade física, psíquica e social, e para utilizar os recursos das redes de saúde e intersetorial para lidar com os problemas que possam surgir nessa fase (BRASIL, 2016).

Pensando na necessidade de ofertar um atendimento qualificado, foi proposta a oficina objetivando capacitar os profissionais e aguçar o pensamento crítico; desta forma foi elegida a metodologia ativa que coloca o profissional no centro do ensino-aprendizagem, como participante ativo desse processo. Essa metodologia proporciona o aprendizado baseado em experiências e uma de suas vantagens é promover a interelação entre a teoria e a prática, que motiva a participação (VARGAS; GONZALEZ; NAVARRETE, 2018).

\section{METODOLOGIA}

Trata-se de um estudo descritivo abrangendo a Oficina: "Eu reconheço sinais de alerta no pré-natal e puerpério" do Projeto de Redução da Mortalidade Materna, que foi ministrada primeiramente pelo Hospital Albert Einstein (SP) em parceria com o Hospital Agamenon Magalhães (PE), buscando capacitar lideranças assistenciais e profissionais da APS; e formar facilitadores que reproduzam a capacitação no município do Recife.

Esses profissionais habilitados facilitadores repassaram os conteúdos da Oficina de prénatal, através de uma metodologia ativa para os profissionais da APS do Distrito Sanitário VII, em de três (03) encontros.

O processo do facilitador na replicação da oficina: - Eu reconheço sinais de alerta no pré-natal, foi:

- Na abertura foi contextualizado o projeto e os desafios para a redução da mortalidade materna.

- Os participantes foram divididos em 6 grupos. Cada grupo com seu facilitador.

- A metodologia ativa "Problem Based Learning" (PBL - Aprendizagem baseada em problemas), foi aplicada nos pequenos grupos, envolvendo os participantes na leitura das referências disponibilizadas- guias, protocolos ou artigos- e questionamentos sobre a aplicação das informações aos problemas do dia a dia. 
- Após a discussão dos temas nos pequenos grupos, os conhecimentos são compartilhados por todos envolvidos, em um grande grupo.

Os materiais utilizados na dinâmica foram cartolina, projetor para apresentação em powerpoint, canetas coloridas, etiquetas auto adesivas para identificação, pastas com material do curso, cópia das referências bibliográficas para trabalho nos pequenos grupos.

\section{RESULTADOS E DISCUSSÕES}

No que se refere ao acompanhamento pré-natal foi evidenciada a necessidade de ser iniciado o mais precocemente possível, de forma integral, e que sejam realizados os exames recomendados, detectadas e tratadas precocemente as alterações, evitando qualquer risco ao binômio mãe-bebê. Tratando-se do período puerperal evidenciou-se que é essencial a continuação do acompanhamento à essa paciente e a nova vida gerada, para prevenção de afecções e redução também dos índices de mortalidade materna.

Chhabra et al. notaram que a metodologia ativa tem demonstrado ser uma técnica efetiva para o desenvolvimento profissional e do pensamento crítico. Uma das principais vantagens do uso da metodologia seria garantir a cada participante a oportunidade de desenvolver habilidades com raciocínio clínico.

O papel do facilitador na metodologia da oficina consistiu em desenvolver problemas relevantes que estimulassem a interpretação de dados científicos e clínicos com a finalidade de aperfeiçoar o tratamento e acompanhamento de condições frequentes no pré-natal e puerpério.

A oficina por sua vez não objetivou apenas disseminar a informação, mas também mostrar aos profissionais como usá-la frente a novas situações e problemas a serem solucionados. Estudos realizados comparando as metodologias tradicionais passivas e a aprendizagem baseada em equipes mostram que a metodologia ativa resulta em desempenhos melhores e maior satisfação dos profissionais, bem como em maior engajamento e participação (NASCIMENTO et al, 2019). Sendo assim, a metodologia ativa usada na oficina foi uma ferramenta de extrema importância por priorizar o trabalho em equipe na resolução dos casos.

\section{CONCLUSÕES}

A mortalidade materna é um grave problema de saúde pública no Brasil e apresenta um grande desafio para os profissionais em geral. Levando em consideração esse problema, o projeto Redução de Mortalidade Materna buscou sensibilizar os profissionais médicos e enfermeiros a conduzir de forma correta o pré-natal e a identificar fatores de risco, como: 
diabetes gestacional, sífilis, infecção do trato urinário, infecção puerperal e síndromes hemorrágicas.

A partir da oficina ofertada pela Secretária Municipal de Saúde de Pernambuco evidenciou a necessidade de ampliar o entendimento clínico para identificação precoce de sinais de alerta às condições ameaçadoras à vida materna e ações de auxilio imediato a serem iniciados pela atenção básica de saúde, sendo assim, busca-se diminuir a incidência de morbimortalidade materna no nosso território.

Desse modo, através de uma metodologia ativa permitiu à construção coletiva da qualificação e aplicabilidade na prática assistencial dos profissionais médicos e enfermeiros do Distrito Sanitário VII a assistência ao pré-natal e puerpério.

\section{REFERÊNCIAS}

ANDRADE, R. D. et al. Fatores relacionados à saúde da mulher no puerpério e repercussões na saúde da criança. Esc. Anna Nery. Rio de Janeiro, v. 19, n. 1, p. 181-186, 2015.

BRASIL. Ministério da Saúde. Caderneta da Gestante. Brasília: Ministério da Saúde, 2018. Disponível em: <http://portalarquivos2.saude.gov.br/images/pdf/2018/agosto/31/Cadernetada-Gestante-2018.pdf.> Acesso em: 03 de julho de 2019.

BRASIL. Ministério da Saúde. Saúde de A a Z. Brasília: Ministério da Saúde, 2019. Disponível em: <http://www.saude.gov.br/saude-de-a-z/gravidez.>. Acesso em: 15 de julho de 2019.

BRASIL. Ministério da Saúde. Protocolo da Atenção Básica: Saúde das Mulheres. Instituto Sírio-Libanês de Ensino e Pesquisa - Brasília: Ministério da Saúde, 2016. Disponível em:< http://bvsms.saude.gov.br/bvs/publicacoes/protocolos_atencao_basica_saude_mulheres.pdf.>. Acesso em: 21 de julho de 2019.

CARVALHO, M.L. et al. Prevenção da mortalidade materna no pré-natal: uma revisão integrativa. R. Interdisciplinar. 8(2):178-184, 2015.

CHHABRA, N. et al. Team-based learning strategy in biochemistry: Perceptions and attitudes of faculty and 1st-Year medical students. Int J App Basic Med Res. 7:S72-7, 2017.

CORREA, M. S. M. et al. Acolhimento no cuidado à saúde da mulher no puerpério. Cad. Saúde Pública. Rio de Janeiro, v. 33, n. 3, 2017.

COUTINHO, E.C. et al. Gravidez e parto: O que muda no estilo de vida das mulheres que se tornam mães?. Rev. esc. enferm-USP. São Paulo, v.48, n.spe2, p.17-24, 2014.

GARCIA, M.B.O.; OLIVEIRA, M.M.; PLANTIER, A. P. Interatividade e Mediação na Prática de Metodologia Ativa: o Uso da Instrução por Colegas e da Tecnologia na Educação Médica. Rev. bras. educ. med. Brasília, v. 43, n. 1, p. 87-96, 2019. 
GOMES, G. F,; SANTOS, A.P.V. Assistência de enfermagem no puerpério. Revista Enfermagem Contemporânea. Bahia, 6 (2):211-220, 2017.

LIVRAMENTO, D.V.P. et al. Percepções de gestantes acerca do cuidado pré-natal na atenção primária à saúde. Rev. Gaúcha Enferm. Porto Alegre, v. 40, e 20180211, 2019.

MARTINS, Q.P.M. et al. Conhecimentos de gestantes no pré-natal: evidencias para o cuidado de enfermagem. S A N A R E, Sobral, V.14, n.02, p.65-71, 2015.

NASCIMENTO, E.N. et al. Aprendizagem Baseada em Equipes na Fonoaudiologia: experiência na formação em Saúde Coletiva. Rev. CEFAC. São Paulo, v. 21, n. 2, e 15918, 2019.

SÁEZ, Z.A. et al. Estudio comparativo de la recuperación postparto en base a los Patrones de Marjory Gordon. Enfermería Global, v. 18, n. 1, p. 183-214, 2018.

VARGAS, I.; GONZALEZ, X.; NAVARRETE, T. Metodología activa en el Estudio de Caso para desarrollo del pensamiento crítico y sentido ético. Enferm. Univ. México, v. 15, n. 3, p. 244-254, 2018. 